\title{
Análises das representações dos professores sobre o currículo cultural da Educação Física *
}

NEIRA, M.G. Analysis of teachers' representations about the Physical Education cultural curriculum. Interface - Comunic., Saude, Educ., v.14, n.35, p.783-95, out./dez. 2010.

The present study discusses the representations of Physical Education teachers who voluntarily participated in an in-context investigation process, with the objective of building and developing curriculums inspired by cultural theorization. Adopting bricolage as a research method, the records of the fortnightly meetings were intertwined with descriptions of the pedagogical practices. By using Cultural Studies to weave the interpretations of the empirical references, it was possible to consider the ideas that emerged as results of the accessed formative processes and of personal positions in relation to the students' cultural heritage.

Keywords: Physical education.

Curriculum. Culture.
No presente estudo discutimos as representações dos professores de Educação Física que, voluntariamente, participaram de um processo de investigação em contexto com o objetivo de construir e desenvolver currículos inspirados na teorização cultural. Adotando a bricolagem como método de pesquisa, os registros das reuniões quinzenais foram entretecidos com os relatos das práticas pedagógicas. Ao se recorrer aos Estudos Culturais para tessitura das interpretações do referencial empírico, foi possível considerar as noções que emergiram como decorrentes dos processos formativos acessados e de posicionamentos pessoais com relação ao patrimônio cultural dos estudantes.

Palavras-chave: Educação física. Currículo. Cultura.

Apoio: CNPq. ${ }^{1}$ Faculdade de Educação, Universidade de São Paulo. Av. da Universidade, 308. Cidade Universitária, São Paulo, SP, Brasil. 05.508-040. mgneira@usp.br 


\section{A problemática}

Há muito que a literatura educacional manifesta algum consenso em torno do reconhecimento da influência do contexto nos procedimentos adotados pelo professor ou nas suas concepções. Consequentemente, nas últimas décadas vêm ganhando visibilidade os estudos que buscam integrar a formação continuada à pesquisa in loco. A investigação no contexto escolar se torna possível à medida que mobiliza os docentes como parceiros ativos de um projeto de transformação (Sarmento, 2003). Graças à relação de parceria, estabelece-se uma dimensão colaborativa de pesquisa que reconhece o papel protagonista do professor no que tange a suas práticas e representações.

Nos anos de 2007 e 2008, conduzimos um projeto de investigação ambientado em sete escolas públicas situadas nos municípios de São Paulo, Barueri, Osasco e São Bernardo do Campo, com o objetivo de construir e desenvolver currículos de Educação Física teoricamente amparados nos referenciais dos Estudos Culturais (EC). Nelson, Treichler e Grossberg (1995) definem os EC como um termo de conveniência para uma gama bastante dispersa de posições teóricas e políticas. Sendo profundamente antidisciplinares, pode-se dizer que partilham o compromisso de examinar práticas culturais do ponto de vista de seu envolvimento com, e no interior de relações de poder.

Os 11 professores ${ }^{2}$ de Educação Física, cujas representações se transformaram em objeto de análise no presente artigo, mostraram-se interessados em implementar currículos inspirados na teorização cultural com base nas discussões travadas durante um evento de extensão universitária do qual participaram. Oriundos de cursos de Licenciatura moldados segundo a Resolução CFE n $03 /$ $87^{3}$, quatro participantes concluíram cursos de especialização na área educacional, enquanto os demais manifestaram envolvimento frequente em eventos de formação contínua desenvolvidos pelos sistemas públicos de ensino. Com relação ao tempo de magistério, os professores, à época do estudo, possuíam de três a sete anos de experiência.

Perfazendo jornadas entre 27 e 35 horas/aula semanais, dentre aqueles que se dedicavam exclusivamente a uma instituição de ensino, dois atuavam na rede estadual; quatro, em escolas da rede municipal de São Paulo; um, na rede municipal de Osasco; e um, na rede municipal de Barueri. Já, entre os professores que atuavam em duas escolas, um acumulava exercícios na rede estadual e na rede municipal paulistana; um trabalhava nas redes municipais de São Bernardo do Campo e São Paulo; e, outro, nas redes municipais de Osasco e São Paulo.

Após reuniões com as equipes gestoras das escolas para esclarecimentos e solicitação formal de autorização para realização do estudo, ao pesquisador coube planejar e desenvolver as atividades formativas e acompanhar a implementação do currículo cultural da Educação Física.

Nos seis meses que antecederam a elaboração do currículo cultural, as reuniões formativas se caracterizaram por um conjunto de atividades que simultaneamente promoviam a reflexão sobre o fazer pedagógico dos participantes e possibilitavam o acesso aos referenciais do currículo cultural da Educação Física que subsidiavam a construção da proposta a ser experimentada. Após a leitura da bibliografia recomendada, foram realizados debates acerca das temáticas ${ }^{4}$ que fundamentam o currículo cultural. Também foram mapeados os saberes culturais corporais de cada comunidade escolar ${ }^{5}$ como estratégia relevante para o planejamento ${ }^{6}$ conjunto das atividades de ensino. Uma vez iniciado o desenvolvimento do currículo cultural, concomitante às discussões
${ }^{2}$ Após as explicações iniciais e leitura do projeto de pesquisa, todos os participantes assinaram um termo de consentimento livre e esclarecido (TCLE).

${ }^{3}$ Essa informação, angariada durante as entrevistas, permitiu fazer conjeturas sobre a relação entre o currículo da formação inicial acessado e as

representações acerca da perspectiva cultural da Educação Física. Na maioria das instituições formativas, segundo Benites, Souza Neto e Hunger (2008), a Resolução CFE nº 03/87 (Brasil, 1987) propiciou a adoção do que se denominou "Licenciatura ampliada", ou seja, "formavam-se profissionais para atuar tanto no espaço escolar quanto no não escolar em virtude da abrangência do seu campo de atuação" (Benites, Souza Neto, Hunger, 2008, p.345). A correção desse problema só ocorreria com a Resolução CNE/CSE nº 07/ 04 que regulamentou percursos distintos conforme o perfil profissional.

${ }^{4}$ Função social da escola na contemporaneidade; teorização curricular da Educação Física; teorias póscríticas da educação e suas influências na Educação Física; e o ensino da Educação Física na perspectiva cultural.

${ }^{5}$ A comunidade escolar é aqui compreendida como estudantes e suas famílias e todos os profissionais que atuam na escola.

${ }^{6}$ Seleção das manifestações corporais que seriam abordadas e proposição das atividades de leitura e interpretação da gestualidade, ressignificação (modificação da manifestação em estudo conforme os significados do grupo), aprofundamento (melhor compreensão da prática corporal a partir do acesso de novas informações sobre ela) e ampliação (estabelecimento de comparações com outras perspectivas sobre a mesma manifestação acessadas mediante fontes externas ao grupo) 
7 Os depoimentos dos participantes foram transcritos em itálico.
${ }^{8}$ Grosso modo, o significante pode ser entendido como a imagem mental de um signo, sem que se estabeleça uma relação direta com o significado. Para Derrida (2002), o significado é uma abstração inalcançável.

Vive-se em contato apenas com significantes que são mobilizados na perseguição dos significados dos signos. promovidas a partir das leituras, as gravações das aulas e o retorno dos alunos às atividades propostas (coletados pelos professores) foram analisados durante as reuniões enquanto recurso formativo e forma de acompanhamento das ações didáticas. A elaboração de instrumentos de avaliação da aprendizagem e a interpretação dos seus resultados também entraram na pauta das discussões, além, é claro, das conversas permeadas por inúmeras trocas de impressões acerca do trabalho em experimentação.

Muito embora retornássemos inúmeras vezes ao ponto, ilustrando, explicando e diversificando as atividades formativas, com remissões frequentes aos referenciais teóricos e às imagens gravadas nas escolas, uma parcela do grupo persistiu em uma visão distorcida com relação à construção do currículo cultural. Mesmo após 24 meses de reuniões, estudo e interlocuções pedagógicas, algumas falas seguiam denotando concepções arraigadas a uma perspectiva curricular baseada na cultura dominante, o que se opunha radicalmente às intenções da proposta: A escola deve ensinar coisas novas; Não podemos ficar naquilo que eles já conhecem; Trabalhar com o repertório deles limitará a aprendizagem .

Tal quadro permitiu intuir que as atividades formativas pouco contribuíam para modificar as representações dos participantes. O provável empecilho que isso representaria para a modificação da política curricular das escolas envolvidas fez surgir a necessidade de elucidar as razões da permanência dessas representações.

A representação inclui as práticas de significação e os sistemas simbólicos por meio dos quais os significados são produzidos, posicionando cada pessoa como sujeito. É por meio dos significados produzidos pelas representações que o homem e a mulher dão sentido à experiência e àquilo que são. (Woodward, 2000, p.17)

Conforme os EC, as representações dos docentes não podem ser concebidas de forma essencialista. Frutos de experiências contextuais refletem visões construídas dialeticamente em meio à socialização cultural. É bastante plausível que, ao longo dos anos, os depoentes tenham acumulado vivências e acessado discursos que os levaram a interiorizar determinados significantes ${ }^{8}$, influenciando, consequentemente, sua atribuição de significados. Se o grupo pretendia elaborar e desenvolver um currículo atento à pedagogia cultural, desvelar os mecanismos que proporcionaram a emergência de tais representações constituía-se, objetivamente, atividade formativa de elevada importância, merecedora, portanto, de uma análise mais profunda. A reflexão sobre o fenômeno levou-nos a duas interpretações inter-relacionadas. Além das dúvidas com relação à forma com que a escola contemporânea lida com a cultura, os professores explicitavam restrições com respeito ao reconhecimento do repertório acessado pelos estudantes nas experiências extraescolares. Ora, nesse ambiente, o mínimo que se poderia esperar era a distorção do significado do currículo cultural da Educação Física, implicando, certamente, dificuldades para levar a cabo as intenções do projeto.

\section{Currículo: um campo de lutas}

Os EC ensinam que o currículo não é um instrumento meramente técnico, neutro ou desvinculado da construção social. Enquanto projeto político que forma novas gerações, o currículo é pensado para garantir a organização, controle, eficiência e regulação da sociedade. Como componente pedagógico, define: formas e organiza conteúdos; os conhecimentos que se ensinam e se aprendem; as experiências desejadas para os estudantes etc. Dado seu teor regulatório, o 
currículo constitui estratégia de política cultural, pois, interfere na produção de representações e identidades.

Silva (2007) adverte que a escolha de conteúdos do currículo privilegia um tema em detrimento de outro, ou seja, mediante a inter-relação de saberes, identidade e poder, são promovidos conhecimentos e valores considerados adequados para as pessoas atuarem no mundo. É fato que, para concretizarem seus projetos de sociedade, aqueles que detêm o poder de decisão sobre o currículo escolhem, validam e legitimam conteúdos e atividades de ensino. Quando agregado ao debate curricular, o campo teórico dos EC questiona quem está autorizado a participar dessas decisões, a que interesses servem os conteúdos selecionados, o que é e o que não é considerado conhecimento válido ou importante para a formação das identidades e, por fim, que identidades pretende formar.

Como qualquer artefato cultural, o currículo forma pessoas como sujeitos particulares. Isso significa que o conhecimento nele transmitido não preexiste nos indivíduos (Silva, 1995). O currículo é uma prática discursiva que transmite regimes de verdade, que se corporifica perante certas narrativas de cidadão e sociedade, construindo sujeitos singulares. O currículo não é apenas uma forma de transmissão cultural, é também um modo de posicionar os sujeitos no interior da cultura. Os EC convidam a se compreender o currículo com base na perspectiva de quem é sujeito do processo de formação.

A preocupação quanto aos sujeitos que o currículo forma é decorrente destes tempos em que a presença da diversidade configura novas formas de comunicação entre comunidades e, portanto, de identidades. A identidade, como conceito, oferece recursos para entendermos a interação de nossa experiência subjetiva do mundo e as paisagens culturais em que as subjetividades se constroem. As identidades são produzidas nas relações entre os sujeitos e na interação entre diferentes culturas e, por não haver consenso, são sempre relações de poder, algumas mais visíveis que outras.

A questão da identidade tornou-se central quanto ao modo com que percebemos a contemporaneidade. Para Hall (2000), se é verdade que temos algum sentimento de pertencimento, este não é predeterminado, sólido ou irrevogável. A identidade é constantemente deslocada para toda parte, ora por experiências confortáveis, ora por vivências perturbadoras.

Trata-se de fruto de um processo discursivo, constituído em meio a circunstâncias históricas e experiências pessoais que levam o sujeito a diferentes identificações ou a assumir determinadas posições que conduzem ou influenciam seus atos. As identidades se efetivam a partir do que se realiza e da repetição e reforço das descrições a respeito do que se faz. A identidade, portanto, se torna aquilo que é descrito. Por assim dizer, compreende-se a identidade como um conjunto de características pelas quais os grupos se definem como grupos e marcam, ao mesmo tempo, aquilo que eles não são.

Contudo, esse pertencimento não é uma essência ou garantido para sempre. O sentimento de pertença é transitório. De acordo com Hall (2000), as identidades são um ponto de apego temporário às posições de sujeito com que as práticas discursivas nos interpelam. Elas se transformam à medida que o sujeito percorre caminhos diversos, age e toma decisões diante de uma variedade de ideias e representações com as quais convive. Tanto a nossa identidade quanto a dos outros - a diferença - são construídas na e por meio da representação. É na estreita ligação entre identidade e representação que localizamos o jogo do poder cultural. O poder está inscrito na representação e é por meio dele que os diversos grupos sociais criam a própria identidade e impõem aos outros a diferença. Mediante a representação, travam-se lutas pela validação e negação de significados (Silva, 2000).

Em meio à diversidade cultural, é na inter-relação entre representação, identidade e poder, que ganha ênfase a chamada política da diferença. Neste movimento social e político, os grupos sociais definem-se por meio de múltiplas dimensões (classe, raça, etnia, gênero, idade, profissão, religião, gostos e preferências diversas etc.), afirmando sua identidade e representação. Nas relações de poder entre esses grupos são definidas as representações e identidades válidas. Por sua vez, os grupos desprovidos do poder de definir resistem à hegemonia das identidades dominantes e lutam pelo direito de se fazerem representar ou controlar a construção e divulgação de sua representação.

Com base no campo dos EC, a pedagogia se articula como ação social corporificada no currículo, buscando a tomada de posição de seus sujeitos na luta por justiça e transformação social. Em virtude de seu compromisso com o exame das práticas culturais a partir de seu envolvimento com e no interior das relações de poder, os EC contribuem para as análises dos efeitos do currículo sobre as identidades que 
${ }^{9}$ Termo empregado por Neira e Nunes (2006) para classifica as propostas curriculares da Educação Física que destinam-se a transmitir conhecimentos relativos à aquisição e manutenção de um estilo de vida fisicamente ativo. interpela. Sua recusa em desvincular a política do poder do processo de escolarização reforça a ideia de que a pedagogia não pode ignorar os fatores que interferem na definição dos significados e das metas da educação.

Ao projetarem as identidades "adequadas" ao projeto social, as políticas educacionais organizam currículos que definem quais posições os sujeitos da educação devem assumir enquanto cidadãos (Silva, 1995). Contudo, diante da possibilidade de se recontextualizarem as diretrizes oficiais e partindo de uma visão de educação como prática cultural responsável politicamente pelas histórias que produz (Giroux, 1995), supomos bem-vinda a emergência de outras propostas curriculares. Propostas que ponham em circulação outras narrativas identitárias, outras linguagens, outras formas de significar a Educação Física, proporcionando, aos seus sujeitos: condições para construir uma agenda crítica preocupada com a cultura e suas conexões com o poder, reconhecer-se enquanto portadores e produtores de conhecimento, validar suas vozes, rejeitar o elitismo e entender a necessidade da constante elaboração de um projeto democrático para a sociedade. Estes são, de forma sumária, os fundamentos do currículo cultural da Educação Física debatidos ao longo das reuniões formativas.

\section{O currículo cultural da Educação Física}

A análise das propostas da Educação Física a partir da teorização crítica aventou que os conteúdos corporificados nos currículos desenvolvimentista, psicomotor, esportivista e saudável ${ }^{9}$ carregam as marcas indeléveis das relações sociais em que foram forjados (Neira, Nunes, 2006). Cada qual, a seu modo, reproduz, culturalmente, a estrutura de classes da sociedade capitalista. Funcionando como aparelhos ideológicos, esses currículos transmitem a ideologia dos grupos melhor posicionados na escala econômica. Resumidamente, as teorias críticas denunciaram a reprodução da desigualdade pelo sistema educacional e suas consequências sobre os sujeitos da educação. Afirmaram a necessidade de uma reflexão mais profunda acerca do que ensinam os currículos, a quem pertencem os conhecimentos neles veiculados, quais identidades legitimam e quais negam.

Recentemente, as teorias pós-críticas, nas quais se enquadram os EC, ampliaram as análises das teorias críticas, fortalecendo a resistência aos ditames da sociedade classista e indicando a existência de relações de poder em outros marcadores sociais: etnia, gênero, religião, tempo de escolarização etc. Buscando inspiração na teorização pós-crítica, Silva (2007) aponta formas alternativas de conceber a educação e o sujeito social. Reafirma o ideal de uma sociedade que considere prioritário o cumprimento do direito que todos os seres humanos têm de ter uma vida digna, ou seja, de ter uma vida em que sejam plenamente satisfeitas suas necessidades vitais, sociais e históricas. Nesse cenário, sinaliza o autor, a educação está estreitamente vinculada à construção de uma sociedade em que riqueza, recursos materiais e simbólicos e condições adequadas sejam mais bem distribuídos. A educação deve ser construída como um espaço público que promova essa possibilidade e como um local em que se forjem identidades sociais democráticas.

Em pesquisa anterior (Neira, 2008), constatamos que um currículo de Educação Física comprometido com essa visão - aqui denominada "cultural" - procura impedir a reprodução consciente ou inconsciente da ideologia dominante, presente, por exemplo, nas propostas que deixam de questionar os inúmeros marcadores sociais que caracterizam as manifestações corporais. O currículo cultural tem como pressuposto básico a recorrência à política da diferença por meio da valorização das vozes daqueles que são quase sempre silenciados (Giroux, 1995). Trata-se de um apelo para que se reconheça que, nas escolas, assim como na sociedade, os 
ANÁLISES DAS REPRESENTAÇÕES DOS PROFESSORES SOBRE O CURRÍCULO ..

significados são produzidos por experiências que precisam ser analisadas em seu sentido político-cultural mais amplo.

Um currículo cultural da Educação Física prestigia, desde seu planejamento, comportamentos democráticos para a decisão dos conteúdos e atividades de ensino. Valoriza a reflexão crítica sobre práticas sociais da cultura corporal do universo vivencial dos alunos para, em seguida, aprofundá-las e ampliá-las mediante o diálogo com outras vozes e outras manifestações corporais. No currículo cultural, a experiência escolar é um campo aberto ao debate, ao encontro de culturas e à confluência da diversidade de manifestações corporais dos variados grupos sociais. É um campo de disseminação de sentidos, de polissemia, de produção de identidades voltadas para a análise, interpretação, questionamento e diálogo entre e a partir das culturas. Na opinião de Canen e Oliveira (2002, p.61), o currículo cultural "valoriza a diversidade e questiona a própria construção das diferenças e, por conseguinte, dos estereótipos e preconceitos contra aqueles percebidos como 'diferentes' no seio de sociedades desiguais e excludentes".

Aceita essa premissa, é de se esperar que o currículo cultural da Educação Física organize situações em que os alunos sejam convidados a refletir acerca da própria cultura corporal e do patrimônio disponível socialmente, bem como da bagagem veiculada por outros grupos. Evidentemente, essas finalidades implicam a busca permanente pela explicitação das possibilidades e limites oriundos da realidade sociopolítico-cultural e econômica enfrentada pelos cidadãos no seu cotidiano, e que condiciona e determina a construção, permanência e transformação das manifestações da cultura corporal.

O currículo cultural da Educação Física tenciona posicionar os estudantes como sujeitos da transformação social e contribuir com a construção de uma sociedade mais democrática e justa. Consequentemente, a prática pedagógica deverá articular-se ao contexto de vida comunitária; apresentar condições para que sejam experimentadas e interpretadas as formas como a cultura corporal é representada no cenário social; ressignificar essas práticas corporais conforme as características do grupo; aprofundar os conhecimentos acerca desse patrimônio e ampliar os saberes dos alunos a respeito da manifestação corporal estudada. Tais preocupações, alertam Neira e Nunes (2006), tencionam fazer "falar", por meio do estudo das manifestações corporais, a voz de várias culturas no tempo e no espaço, além de problematizar as relações de poder explícitas e implícitas.

Para Garcia (1995), ao situar, no currículo, os conhecimentos que os alunos trazem quando entram na escola, o professor os reconhece como sujeitos de conhecimento, sujeitos capazes - capacidade esta revelada e reconhecida no já sabido, e capacidade potencial para se apropriar de novos conhecimentos que a escola pode e deve oferecer. Com isso, pretende-se não só a valorização identitária, como, também, a ampliação cultural e o reconhecimento das diferenças. Somente o diálogo cultural contribuirá para a construção do autoconceito positivo e respeito com o outro, elementos indispensáveis a uma relação democrática.

\section{A bricolagem}

Os métodos analíticos empregados pelos EC apelam para qualquer campo teórico que colabore para produzir o conhecimento exigido por um projeto particular. Sua proposta pode ser vista como uma "bricolagem" de métodos de pesquisa. Ao questionar as formas positivistas de produzir conhecimento, os EC recorrem a múltiplas leituras de mundo, suscitando interessantes possibilidades quando o foco recai sobre as representações atribuídas a qualquer prática cultural, no caso em tela, o currículo cultural da Educação Física.

A opção pela bricolagem busca dar coerência aos posicionamentos político e epistemológico que inspiraram a presente investigação. Baseamo-nos no fato de que não é possível provocar transformações e mudanças nos quadros sociais sem modificar ou alterar as estruturas e hierarquias que regem a produção dos conhecimentos científicos.

Kincheloe e Berry (2007) explicam que, no contexto da pesquisa, o termo bricolagem é compreendido como o emprego de variados métodos e estratégias à medida que se tornam necessários no desenrolar da investigação. Adotando uma postura ativa, a bricolagem rejeita diretrizes e roteiros 
${ }^{10}$ Lankshear e Knobel (2008) sugerem a utilização de dispositivos de evocação como estratégia para suscitar posicionamentos dos sujeitos da pesquisa acerca de um determinado tema.

${ }^{11}$ Originalmente proposto por Nietsche, o termo "genealogia" foi desenvolvido por Foucault (1992) para descrever o processo de recordar e incorporar as memórias de conhecimentos subordinados, de conflito e as dimensões de poder que revelam as lutas atuais. preexistentes, solicita ou, até mesmo, cria os processos de investigação à medida que surgem as demandas. A bricolagem permite que as circunstâncias deem forma aos métodos empregados. Nenhum método pode ser privilegiado ou empregado com segurança, tampouco descartado antecipadamente.

Apesar de sua multilogicidade, fazer bricolagem implica selecionar métodos, estratégias e referenciais teóricos. Atentos à possibilidade de se construírem novos sentidos e perguntas sobre o objeto investigado sem jamais se apresentarem respostas ou verdades definitivas, recorremos à etnografia e à pesquisa-ação que, entrecruzadas pelos EC, coadunam com o objetivo do presente estudo. A etnografia, por considerar a prática pedagógica dos participantes e reconhecer suas visões do contexto educativo e social, e a pesquisa-ação, por suscitar a transformação dos posicionamentos com relação ao currículo da Educação Física.

Diante da pluralidade de ações às quais um bricoleur pode recorrer, em consonância com os métodos empregados, observamos e filmamos o currículo em ação nas escolas. As imagens coletadas constituíram dispositivos de evocação ${ }^{10}$ durante as atividades formativas desenvolvidas com os participantes. Para uma compreensão mais apurada das concepções docentes, foram realizadas entrevistas, e recolhidos os relatórios alusivos à experiência com o currículo cultural. Os procedimentos e instrumentos adotados permitiram reunir um variado referencial empírico: diário das observações de campo, atas das reuniões, transcrição dos depoimentos docentes e toda a documentação pedagógica.

Com o foco nas representações veiculadas pelos professores colaboradores com relação ao patrimônio cultural da comunidade, à pedagogia proposta e aos pressupostos teóricos que a fundamentam, analisamos criticamente os materiais resultantes, procurando confrontá-los com o arcabouço teórico dos EC. Num primeiro momento, procuramos desconstruir as representações atribuídas ao currículo cultural da Educação Física explicitadas pelos sujeitos. Em seguida, prosseguindo com a análise, recorremos à genealogia ${ }^{11}$ para entretecer diferentes interpretações.

Na bricolagem as análises são entretecidas (Kincheloe, Berry, 2007). Entretecer significa tecer juntos, tecer entremeando. $\mathrm{O}$ ato de entretecer fundamenta uma concepção de pesquisa que pretende construir com base em uma perspectiva crítica, questionadora, dialógica e dialética. Tecer juntos, entremeando, almeja uma produção coletiva de conhecimentos, respeitadora de múltiplas perspectivas e que contemple o ir e vir, o relativo, o temporário e o imprevisível da complexidade contemporânea.

O entretecer é uma ação contínua e constante, configura a bricolagem como recurso para a interpretação e construção de conhecimentos acerca da realidade. Ao promover o entretecimento, ou seja, a tessitura de diferentes posicionamentos, a bricolagem rompe com a arrogância de uma interpretação unívoca a fim de favorecer a multiplicidade de vozes e interpretações acerca da prática social em foco.

Para entretecer as representações acerca do currículo cultural da Educação Física, procuramos ouvir os sujeitos, ler seus relatos, observar suas práticas e compreender os pressupostos que sustentam seus argumentos. Todo e qualquer sujeito produz teses e teorias sobre qualquer fenômeno. Todavia, suas explicações são carregadas dos valores que compartilha, lembrando que os discursos não são produtos individuais, mas de grupos, de coletivos, de instituições.

A bricolagem baseia-se numa constante interação e realimentação por novos posicionamentos e análises. O processo de realimentação é contínuo e não quantificável. Dependendo das informações que surgirem, as interpretações iniciais poderão ser reorganizadas. É esse ir e vir que dá consistência ao 
conhecimento produzido, ou seja, o rigor e a validade. A interpretação na bricolagem não possui um método. $\mathrm{O}$ ato interpretativo promove o desvendar de significados e sentidos expressos pelos diferentes participantes, sendo a tarefa do pesquisador analisar como são construídas essas representações. Assim, o referencial teórico cumpre o papel de subsidiar o olhar do pesquisador para enxergar as relações existentes entre os diferentes discursos e interpretações que fazem da realidade.

$\mathrm{Na}$ bricolagem, o pesquisador chega a um texto com interpretações múltiplas, mas nem sempre conciliáveis sobre o objeto de pesquisa. Não existe explicação verdadeira, conclusão do estudo ou considerações finais, afinal, o conhecimento é transitório e está sempre em processo. É impossível produzir uma explicação completa sobre determinado fenômeno social, pois, a complexa natureza das relações embutidas não permite que isso aconteça. Ao concordarmos com Kincheloe e Berry (2007, p.112) quando afirmam que "todas as descrições do mundo são uma interpretação e sempre há novas interpretações a serem encontradas", afirmamos que as análises a seguir são apenas interpretações passageiras.

\section{Desconstruindo as representações do currículo cultural}

O currículo cultural da Educação Física traz para o interior da escola uma variada gama de manifestações corporais para submetê-las a um permanente processo de tematização. Seguindo o raciocínio de Corazza (2003), tematizar significa abordar algumas das infinitas possibilidades que podem emergir a partir de leituras e interpretações da prática social da manifestação. Tematizar, na visão de Freire (1980), implica procurar o maior compromisso possível do objeto de estudo numa realidade de fato, social, cultural e política. O que se pretende com a tematização é uma compreensão profunda da prática corporal em foco e o desenvolvimento da capacidade crítica dos alunos enquanto sujeitos de conhecimento, desafiados pelo objeto a ser conhecido. Portanto, não se trata de "perguntar aos alunos o que querem estudar", nem tampouco de um empreendimento espontaneísta baseado no laisse faire, conforme afirmado pelos participantes da pesquisa. Enquanto alguns chegaram a dizer que, no currículo cultural, "os alunos escolhem o que querem fazer", outros viam as chamadas "aulas livres" como situações em que a cultura da comunidade era valorizada. Tais representações foram verbalizadas diversas vezes ao longo da investigação.

Dada a variedade de grupos culturais que compõem a sociedade contemporânea, para promover uma trajetória formativa democrática, temos, nas palavras de Connell (1993), que instaurar a justiça curricular. Reconhecendo o valor de todas as identidades, o currículo cultural da Educação Física deve atentar à distribuição equilibrada de diversas manifestações culturais corporais. Para fazer dialogar a multiplicidade, convém reconhecer o patrimônio cultural corporal dos grupos que constituem a sociedade e eleger, a partir dele, as manifestações que serão estudadas. Uma atenta seleção, seguida de interpretação, aprofundamento e ampliação dos saberes, possibilitará o entendimento da heterogeneidade social, contribuindo para democratizar as identidades e valorizar a diversidade cultural corporal.

Tais objetivos foram pouco traduzidos nas práticas pedagógicas, conforme anunciam os relatos dos participantes: "Organizei a atividade de modo a garantir as mesmas experiências para todos"; "Todo mundo tinha que viver a situação de pegador" ou "A bola deve passar pelas mãos de todos". Movidos por uma "igualdade" que camufla noções deterministas de "cultura comum", as falas dos professores indicam suas preocupações com a estruturação de situações didáticas em que os todos os alunos atuem da mesma forma, requisitando, portanto, os mesmos conhecimentos. Os educadores, quando portadores desse pensamento, comumente afirmam que todos os alunos são iguais e, portanto, necessitam das mesmas experiências educacionais para serem bem-sucedidos. Na visão de Stoer e Cortesão (1999), o que se está promovendo é a homogeneização da diversidade que caracteriza os estudantes. Esse daltonismo cultural, explicam os autores, recorre a intervenções pedagógicas que distorcem a igualdade, pois, tendem a tratar a todos da mesma forma, tencionando o alcance de comportamentos idênticos. Mormente, o resultado é o privilégio atribuído àqueles que dispõem de experiências culturais anteriores vinculadas às práticas corporais trabalhadas em aula, o que só faz reforçar certas identidades e desqualificar outras, ou seja, excluem-se os estudantes cuja cultura de chegada se distancia das vivências solicitadas, marcando negativamente as diferenças. 
Na visão do grupo que participou do estudo, a prática pedagógica que caracteriza o currículo cultural, por vezes, foi vista como desperdício de tempo. Para alguns, seria melhor "colocar rapidamente os alunos em movimento". Sempre que as filmagens das aulas ou depoimentos dos colegas que se deixavam inspirar pela proposta apresentavam atividades de leitura, discussão, escrita, pesquisa, assistência a vídeos ou debates entre os alunos, surgiam locuções de rejeição ou escárnio - "Educação Física não é lição" ou "não dá para dar aula teórica" -, proferidas antes que pudessem entender o que estava sendo feito. Notamos que a resistência a um outro formato de atividades de ensino obstaculizava a necessária compreensão do significado dos conteúdos em tela.

Mesmo reconhecendo a existência de outras posturas, Grant e Wieczorek (2000) são enfáticos ao relacionar o currículo cultural às práticas pedagógicas pautadas na ancoragem social dos conteúdos. Trata-se de uma séria análise sócio-histórica e política das manifestações corporais presentes no currículo, adotando a prática social como ponto de partida. O que está em jogo é a compreensão e posicionamento críticos diante do contexto social de produção e reprodução da cultura corporal. Em outras palavras, é necessário descobrir como surge, ocorre e se transforma a manifestação corporal objeto de estudo, para que os alunos possam vivenciá-la e adaptá-la conforme as características do grupo e da escola. Dessa forma, reproduzem-se, com as devidas modificações, as microrrelações que caracterizam o processo de ressignificação de qualquer artefato cultural, posicionando os estudantes na condição de produtores culturais.

A viabilização desse processo leva em conta as experiências pessoais referentes ao tema e os conhecimentos veiculados pelos meios de comunicação de massa, obras específicas, histórias, depoimentos etc. A condução de atividades de ensino pautadas na ancoragem social, ao abordar variadas narrativas, potencializa o diálogo entre o senso comum, a cultura acadêmica e os conhecimentos acessados em outros ambientes, além de ajudar os alunos a elucidarem os discursos que legitimam determinadas experiências e desqualificam outras. O que permite superar a alienação provocada pela veiculação de informações fantasiosas e reconhecer uma nova visão sobre os conhecimentos disponíveis relativos à cultura corporal, sejam eles socialmente valorizados ou marginalizados.

\section{Entretecendo interpretações}

A análise da documentação pedagógica - no caso, o mapeamento do patrimônio cultural corporal da comunidade realizado pelos professores como estratégia para construção do currículo cultural - revelou a existência de diversas manifestações até então "esquecidas" pelas propostas da Educação Física baseadas na transmissão da cultura dominante. Acatando as recomendações sugeridas durante as reuniões formativas, os participantes puderam arrolar uma quantidade de práticas corporais que julgavam desconhecidas pelos estudantes. Emergiram inúmeras brincadeiras; danças da cultura popular, como forró e maculelê; práticas esportivas, como bocha e malha; modalidades radicais, como skate, bicicross e le parkour; danças contemporâneas, como psy e rebolation, entre tantas outras práticas corporais que poderiam compor o currículo cultural.

Quando o currículo cultural valoriza o patrimônio de chegada dos estudantes, quando procura hibridizar suas vozes com aquelas oriundas da cultura dominante, quando reconhece as diferenças, promove a justiça e busca lastrear os conteúdos de ensino, no limite, está defendendo uma política pedagógica absolutamente distinta das acessadas pelos docentes nos seus anos de escolarização. Ou seja, nossos informantes possuíam representações de escola, sociedade, função do professor e prática de ensino que, por ventura, se afastavam do que se propunha nos encontros de formação.

As informações obtidas por meio das entrevistas revelam que os participantes, quando alunos da Educação Básica, experimentaram relações pedagógicas inversas àquelas que caracterizam o currículo cultural: "No meu tempo, ninguém perguntava o que os alunos sabiam"; "Chegava na aula e o professor demonstrava e explicava, a gente fazia"; "Às vezes eu sinto que ensino do mesmo jeito que aprendi"; "Como havia os campeonatos da secretaria, meus professores só davam treinamento"; "Tinha os exercícios que a professora dava todo o ano". Bernstein (1998) diria que, mediante tais experiências, os códigos acessados pelos alunos indicarão que a instituição educativa e os órgãos administrativos são os únicos capacitados a definir o que e o como ensinar. Diante desse quadro de opressão em que foram 
socializados os entrevistados, é compreensível que a assunção da autoria curricular pelo coletivo escolar, conforme propõe o currículo cultural, seja vista como algo improcedente.

A passividade diante da política curricular adquirida durante os anos de escolarização básica, ao que tudo indica, se consolidou nos bancos universitários: "Aprendi assim na faculdade. Lá cobravam a execução dos movimentos"; "Alguns professores valorizavam mais a prática do que a teoria"; "Diziam que aprenderia a ensinar, mas aprendi, principalmente, a fazer"; "No curso que frequentei, a maior preocupação era ensinar treinamento físico".

Investigando o tema, Neira (2007) concluiu que uma parcela considerável dos projetos pedagógicos dos cursos de Licenciatura em Educação Física exprime concepções destoantes com relação aos atuais pressupostos que fundamentam a docência. A maioria impinge aos futuros professores conteúdos desnecessários a quem vai trabalhar na escola, deixando de lado questões primordiais. Muitos cursos superiores ainda ensinam o preenchimento de súmulas esportivas, exigem o desempenho atlético e, sobretudo, priorizam disciplinas biológicas em detrimento das pedagógicas. Os universitários, quando interpelados, queixam-se da capacidade didática ou das avaliações propostas pelos professores, quase nunca questionam os conteúdos ensinados. Aprenderam a aceitá-los mesmo sem conhecer suas origens, razões e relações com a docência.

Sob a influência das teorias pós-críticas, é possível questionar a atualidade dos conteúdos presentes nos currículos que formam professores: quais são os códigos transmitidos quando se desconsidera que ensinar Educação Física numa escola democrática, compulsória e multicultural significa recorrer ao diálogo, respeito e valorização da cultura patrimonial? Quais representações sobre a profissão, alunos, escolas, ensino, papel do componente etc., são transmitidas quando o desempenho esportivo é destacado? É importante frisar que ao se ofertarem certas experiências e conteúdos, e não outros, formar-se-ão determinadas identidades docentes, e não outras. Qualquer decisão curricular é política. Qualquer decisão curricular vincula-se a um modo de ver o mundo que se quer legitimar e tornar hegemônico. Com isso, qualquer decisão curricular contempla alguns e afasta os demais.

Os saberes e situações que constituem o currículo da formação para a docência refletem, em última análise, o sujeito que se quer formar. Sempre há um projeto de cidadão em vista e, no caso da formação inicial, um perfil profissional a ser alcançado para um determinado projeto de sociedade. Se concordarmos com a assertiva de Silva (2007), para quem o currículo forja pessoas, constitui identidades, somos obrigados a perguntar se pretendemos formar identidades profissionais docentes mais alinhadas à manutenção ou à transformação do atual quadro social.

Em suma, ao explicitarmos que os currículos escolares e universitários, consciente ou inconscientemente, se vinculam a determinados setores, grupos, conhecimentos, correntes e tendências, atribuímos à trajetória formativa, vivida pelos participantes do estudo, uma parcela da responsabilidade pelo teor das representações que possuíam acerca do currículo cultural da Educação Física. Avaliamos que a repetição de códigos opressores ao longo de toda formação básica e superior contribuíram para a adoção de uma postura heterônoma diante do currículo.

No tocante à incorporação do repertório cultural da comunidade, outra característica marcante da perspectiva cultural, grande parte do grupo investigado se mostrou reticente: "O que está na cultura deles? Só dançam funk, rap, jogam videogame, essas coisas"; "Na hora do recreio eles já fazem isso, na aula, é melhor aprender coisas úteis". Na visão dos participantes, nota-se que somente os conteúdos extraídos da cultura dominante poderão mudar as condições de vida dos alunos.

Kincheloe e Steinberg (1999) enxergam, nesse posicionamento, uma forma de etnocentrismo, pois desqualifica o patrimônio alheio em prol da visão pessoal. Um currículo centrado nos conhecimentos hegemônicos provavelmente desencadeará o sentimento de superioridade nos representes da elite e inferioridade nos demais. Por isso, não é de se estranhar a condição de fracasso enfrentada por aqueles que não se reconhecem no currículo. Ao repelirem por meio de práticas pedagógicas impositivas o repertório cultural dos alunos, os docentes, em certa medida, camuflam seus preconceitos, aludindo à inferioridade daqueles por meio de insinuações sobre seus valores familiares ou sobre o que configura a 
forma ideal de ser, agir e pensar. Em tal cenário, os comportamentos ideais são naturalizados, servindo para justificar e fundamentar posturas opressoras com relação aos que se encontram à margem, posto que, presumivelmente, são carentes ou incapazes e, por essa razão, não conseguem aprender os conteúdos ensinados.

McLaren (2003) alerta que uma das formas encontradas pelos setores dominantes para pasteurizar a presença da diversidade cultural na escola é o constante apelo à "cultura comum" concretizada nos currículos unificados. Um dos indícios desse pensamento, frequentemente mencionado nas reuniões formativas, consistiu na defesa intransigente de uma só proposta curricular de Educação Física. Seus porta-vozes aludiram à facilidade que isso representaria para eles e os benefícios para os alunos: "Todos já saberiam o que ensinar a cada ano" e "Na quinta série é aquilo e pronto, os alunos não reclamariam". Nega-se a cultura da comunidade quando se propõe um currículo planejado centralmente e uniforme para todos os alunos e todas as escolas, independentemente das características e condições de implementação. O currículo uniforme é insensível aos interesses e necessidades dos estudantes e da escola. A consequência, segundo o autor, é o silenciamento das vozes dos alunos menos favorecidos em razão da sua condição social.

A análise dos relatos e depoimentos indica que, enquanto a maior parcela dos sujeitos atuava no sentido da manutenção das condições vigentes, preservando a todo custo a inviolabilidade dos conteúdos hegemônicos da Educação Física, aludindo a uma certa tradição da área, outros ousaram, transgrediram e experimentaram mudanças. Essa ocorrência denota a dialeticidade que caracteriza a relação dos sujeitos com as práticas culturais. Daí a importância de se proporcionarem situações formativas que priorizaram o debate, a reflexão e a análise profunda sobre a realidade que cerca a escola contemporânea e a docência da Educação Física. Afinal, conforme Giroux (1995), não há somente passividade diante da cultura, há, também, resistência e ressignificação. Em função disso, é possível dizer que, a seu modo, alguns professores que colaboraram com a investigação ensejaram avanços na construção e desenvolvimento de currículos inspirados na teorização cultural.

Findado o período de permanência nas instituições que acolheram o estudo, simplesmente responsabilizar os participantes pela sua compreensão acerca da proposta é um equívoco. A genealogia que proporcionou o entretecimento das interpretações permite afirmar que os significados atribuídos ao currículo cultural da Educação Física se encontram profundamente vinculados às trajetórias formativas. Quando negligenciam os conhecimentos dos estudantes e defendem uma pedagogia salvacionista, os docentes revelam sua fé naquilo que sabem e na forma como sabem ensinar. Há que se dizer, no entanto, que não se trata de um posicionamento cristalizado ou definitivo. Afinal, o estudo desenvolvido traz esperanças acerca da ressignificação das representações docentes.

Apesar das modificações constatadas nas concepções de diversos participantes, na nossa perspectiva, a maior contribuição da investigação diz respeito à compreensão dos mecanismos que geram a resistência e distanciamento com relação ao currículo cultural - como se constatou, tanto os processos formativos acessados quanto os posicionamentos pessoais com relação ao tratamento pedagógico dos saberes oriundos dos grupos minoritários mostram-se como empecilhos ao entendimento da proposta.

Como fator limitante do estudo desenvolvido não pode ser desconsiderado o fato de que os sujeitos da cultura encontram-se em processos dinâmicos de significação, sendo bastante variados os aspectos que influem na construção de identidades. É bem possível que os sujeitos investigados sigam modificando suas representações acerca do currículo cultural da Educação Física, independentemente da participação em atividades formativas.

Uma vez reconhecido o emaranhado que leva os sujeitos a elaborarem determinadas representações a respeito do currículo cultural, é possível empreender ações voltadas para a transformação. Inspirados nos EC, se indagarmos com mais frequência e intensidade sobre o etnocentrismo pedagógico que povoa os currículos que formam professores de Educação Física, será possível desconstruir práticas curriculares engessadas e evitar que o oprimido de hoje se transforme no opressor de amanhã, perpetuando indefinidamente o ciclo. 


\section{Referências}

BENITES, L.C.; SOUZA NETO, S.; HUNGER, D. O processo de constituição histórica das diretrizes curriculares na formação de professores de Educação Física. Educ. Pesqui., v.34, n.2, p.343-60, 2008.

BERNSTEIN, B. Pedagogia, control simbólico e identidad. Madrid: Morata, 1998.

BRASIL. Conselho Federal de Educação. Resolução n 3/87, de 16 de junho de 1987. Fixa os mínimos de conteúdo e duração a serem observados nos cursos de graduação em Educação Física (Bacharelado e/ou Licenciatura Plena). Diário Oficial da União, Brasília, DF, 22 junho 1987, p.9635-6.

CANEN, A.; OLIVEIRA, A.M.A. Multiculturalismo e currículo em ação: um estudo de caso. Rev. Bras. Educ., n.21, p.61-74, 2002.

CONNELL, R.W. Schools and social justice. Montréal: Our Schools/Our Selves Education Foundation, 1993.

CORAZZA, S.M. Tema gerador: concepções e práticas. Ijuí: Editora Unijui, 2003.

DERRIDA, J. A escritura e a diferença. São Paulo: Perspectiva, 2002.

FOUCAULT, M. Microfísica do poder. Rio de Janeiro: Graal, 1992.

FREIRE, P. Conscientização: teoria e prática da libertação - uma introdução ao pensamento de Paulo Freire. São Paulo: Moraes, 1980.

GARCIA, R.L. Currículo emancipatório e multiculturalismo: reflexões de viagem. In: SILVA, T.T.; MOREIRA, A.F. (Orgs.). Territórios contestados: o currículo e os novos mapas políticos e culturais. Petrópolis: Vozes, 1995. p.114-43.

GIROUX, H. Praticando estudos culturais nas Faculdades de Educação. In: SILVA, T.T. (Org.). Alienígenas na sala de aula: uma introdução aos estudos culturais em educação. Rio de Janeiro: Vozes, 1995. p.132-58.

GRANT, C.A.; WIECZOREK, K. Teacher education and knowledge in the "knowledge society": the need for social moorings in our multicultural schools. Teach. Coll. Rec., v.102, n.5, p.913-35, 2000.

HALL, S. Quem precisa de identidade? In: SILVA, T.T. (Org.). Identidade e diferença: a perspectiva dos Estudos Culturais. Petropólis: Vozes, 2000. p.103-33.

KINCHELOE, J.L.; BERRY, K.S. Pesquisa em educação: conceituando a bricolagem. Porto Alegre: Artmed, 2007.

KINCHELOE, J.L.; STEINBERG, S.R. Repensar el multiculturalismo. Barcelona: Octaedro, 1999.

LANKSHEAR, C.; KNOBEL, M. Pesquisa pedagógica: do projeto à implementação. Porto Alegre: Artmed, 2008.

MCLAREN, P. Multiculturalismo revolucionário: pedagogia do dissenso para novo milênio. Porto Alegre: Artmed, 2003.

NEIRA, M.G. A cultura corporal popular como conteúdo do currículo multicultural da Educação Física. Pensar a Prática, v.11, n.1, p.81-90, 2008.

Ensino de Educação Física. São Paulo: Thomsom Learning, 2007.

NEIRA, M.G.; NUNES, M.L.F. Pedagogia da cultura corporal: crítica e alternativas. São Paulo: Phorte, 2006.

NELSON, C.; TREICHLER, P.A.; GROSSBERG, L. Estudos Culturais: uma introdução. In: SILVA, T.T. (Org.). Alienígenas na sala de aula: uma introdução aos estudos culturais em educação. Rio de Janeiro: Vozes, 1995. p.7-38. 
SARMENTO, M.J. Quotidianos densos: a pesquisa sociológica dos contextos de acção educativa. In: GARCIA, R.L. (Org.). Método, métodos, contramétodo. São Paulo: Cortez, 2003. p.91-110.

SILVA, T.T. Documentos de identidade: uma introdução às teorias do currículo. Belo Horizonte: Autêntica, 2007.

A produção social da identidade e da diferença. In: (Org.). Identidade e diferença: a perspectiva dos Estudos Culturais. Petrópolis: Vozes, 2000. p.73-102.

Currículo e identidade social: territórios contestados. In: (Org.). Alienígenas na sala de aula: uma introdução aos estudos culturais em educação. Rio de Janeiro: Vozes, 1995. p.190-207.

STOER, S.R.; CORTESÃO, L. Levantando a pedra: da pedagogia inter/multicultural às políticas educativas numa época de transnacionalização. Porto: Afrontamento, 1999.

WOODWARD, K. Identidade e diferença: uma introdução teórica e conceitual. In: SILVA, T.T. (Org.). Identidade e diferença: a perspectiva dos Estudos Culturais. Petrópolis: Vozes, 2000. p.7-72.

NEIRA, M.G. Análisis de las representaciones de los profesores sobre el currículo cultural de la Educación Física. Interface - Comunic., Saude, Educ., v.14, n.35, p.783-95, out./dez. 2010.

En el presente estudio discutimos las representaciones de los profesores de Educación Física que, voluntariamente, han participado de un proceso de investigación en contexto con el objetivo de construir y desarrollar currículos inspirados en la teorización cultural. Adoptando el bricolaje como método de investigación, los registros de las reuniones quincenales fueron entretejidos con los relatos e las prácticas pedagógicas. Al recorrer a los Estudios Culturales para tesitura de las interpretaciones del referencial empírico, ha sido posible considerar las nociones que emergieron como consecuencia de los procesos formativos accedidos y de posicionamientos personales con relación al patrimonio cultural de los estudiantes.

Palabras clave: Educación física. Currículo. Cultura. 